\title{
ADEQUAÇÃO DAS PRÁTICAS DE OPERAÇÃO E MANUTENÇÃO DE SITES INDUSTRIAIS AOS REQUISITOS DE SEGURANÇA DA NR-10: CASOS REAIS*
}

\section{Resumo}

Francisco Vitor Vasques Barbosa ${ }^{1}$ Luis Antonio Brito Leal ${ }^{2}$

Após 10 anos da aprovação da portaria 598 do Ministério do Trabalho, e ter realizado Laudo de Inspeção em mais de 60 sites industriais de grande porte, a PDCA Engenharia tem sido envolvida no processo de adequação do sistema de gestão de manutenção e operação das instalações elétricas de seus clientes. $O$ relatório de inspeção preconizado no item 10.2.4.g da NR-10 estabelece a obrigatoriedade de se levantar os aspectos não conformes, estabelecer um plano de adequação definindo responsáveis e prazo de execução. Com os efetivos de manutenção reduzidos, nossos clientes passaram a envolver a PDCA na implementação das ações de adequação. Este trabalho consiste entre outras coisas na identificação das intervenções críticas de operação e manutenção das instalações elétricas (15 a 20 no máximo por site), analisá-las do ponto de vista dos riscos elétricos e adicionais associados a cada etapa de execução, estabelecer as medidas de controle necessárias para a mitigação destes riscos, redigir procedimentos e treinar o pessoal envolvido. Outros procedimentos devem trabalhar a eliminação dos riscos para os trabalhadores não autorizados (leigos), que interajam indiretamente em instalações elétricas e serviços com eletricidade. Apresentamos um resumo desta experiência recente com clientes da área Química/Petroquímica e da área de Logística.

Palavras Chave: NR-10; Adequação; Procedimentos; Intervenções.

\section{SUITABILITY OF OPERATION AND MAINTENANCE PRACTICES OF INDUSTRIAL SITES TO SAFETY REQUIREMENTS OF NR-10: REAL CASES}

\section{Abstract}

Ten years after the adoption of Ordinance 598 of the Ministry of Labour, and have held Valuation Inspection in more than 60 industrial large sites, the PDCA Engineering became involved in the suitability of the maintenance management system and operation of power process facilities of their customers. The inspection report recommended of the item 10.2.4.g NR - 10 establishes the obligation to indicate the issues that DO NOT COMPLY, establish a fitness plan defining responsible and execution time. With the decreasing number of maintenance workers, our customers started share with PDCA the adequacy actions. The work consists, among other things, to identify the critical interventions to the operation and maintenance of electrical installations (15 to 20 at most), analyze them in terms of electrical hazards and additional risks associated with each intervention step, establish the necessary control measures to mitigate these risks, develop procedures and train the involved staff. Other procedures look for the elimination of risks for unauthorized workers (lays) that interact indirectly in electrical facilities and with any other work in electricity. We present a summary of recent experience with clients of Chemical / Petrochemical area and the Logistics area.

Keywords: NR-10; Suitability; Procedures; Interventions

Engenheiro eletricista, gestor, PDCA Engenharia, Campinas, São Paulo, Brasil.

Engenheiro Eletricista, Engenheiro Associado, PDCA Engenharia, Campinas, SP, Brasil.

\footnotetext{
* Contribuição técnica ao $35^{\circ}$ Seminário de Balanços Energéticos Globais e Utilidades e $29^{\circ}$ Encontro de Produtores e Consumidores de Gases Industriais, 13 a 15 de agosto de 2014, São Paulo, SP, Brasil.
} 
Seminário de Energia \& Utilidades

$35^{\circ}$ Seminário de Balanços Energéticos Globais e Utilidades \& $29^{\circ}$ Encontro de

Produtores $\mathrm{e}$ Consumidores de Gases Industriais

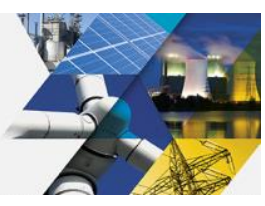

\section{INTRODUÇÃO}

A Norma Regulamentadora n. 10 - Segurança em Instalações e Serviços em Eletricidade (NR-10), em sua revisão aprovada pelo Ministério do Trabalho e Emprego em 2004, dispõe sobre as diretrizes básicas para a implementação de medidas de controle e sistemas preventivos, destinados a garantir a segurança e a saúde dos trabalhadores que direta ou indiretamente interajam em instalações elétricas, nos seus mais diversos usos e aplicações, e nos serviços com eletricidade, abrangendo quaisquer trabalhos realizados nas suas proximidades. Como Norma Regulamentadora do MTE tem força de Lei e o seu cumprimento é obrigatório.

As empresas brasileiras foram aos poucos se conscientizando da importância de se adequarem a ela. Começaram paulatinamente a demandar serviços de avaliação da condição de segurança das instalações elétricas e métodos de trabalho, e com isso tiveram acesso a relatórios técnicos estabelecendo onde e como agir. Tais relatórios são exigidos pela NR-10 em seu item 10.2.4 alínea g, o qual embute a necessidade de um plano de adequação, definindo responsáveis e prazos para a sua execução.

Nesses 10 anos após a revisão da norma, período no qual a PDCA Engenharia realizou Laudo de Inspeção em mais de 60 sites industriais de grande e médio porte, temos percebido que nem sempre os responsáveis pela gestão dos sistemas elétricos das empresas conseguem ser suficientemente perseverantes na perseguição das metas então estabelecidas. As preocupações e o envolvimento com o dia a dia da empresa (operação dos sistemas, manutenção corretiva pontual, planejamentos e execução dos trabalhos nas paradas gerais do sistema produtivo, administração de pessoal, aspectos burocráticos relativos a contratação e fiscalização de serviços de terceiros, etc.) e a prioridade sempre alta que se dá à solução de problemas que afetam diretamente a produção, impedem uma dedicação adequada.

Para enfrentar essa realidade, mais recentemente nossos clientes passaram a envolver a PDCA também para auxiliá-los nas ações pós-relatório de avaliação.

O objetivo deste trabalho é apresentar as ações desenvolvidas pela PDCA junto a seus clientes, onde teve a oportunidade de auxiliá-los no desenvolvimento e implantação de procedimentos voltados para a gestão e intervenções nas instalações elétricas de seus sites.

\section{METODOLOGIA}

O método utilizado parte do princípio que o concurso de terceiros visa garantir a realização de um trabalho importante e necessário para a empresa, que em condições normais não tem recursos humanos em número suficiente para a sua realização. A coordenação do processo é da empresa contratada, porém a participação e o comprometimento dos profissionais de manutenção e operação das instalações elétricas internos da empresa é fator preponderante para o sucesso do trabalho.

Dentro dessa ótica coube à PDCA a execução e à empresa cliente avaliar e validar cada passo do trabalho.

O sucesso dependeu fundamentalmente do envolvimento da alta gerencia, demonstrando aos profissionais envolvidos no processo, a importância e a necessidade da sua participação e colaboração, criando desta forma a disponibilidade de tempo requerida. Isso, sem dúvida, facilitou o agendamento das reuniões que se fizeram necessárias e foi fator decisivo para que o trabalho resultante passasse a fazer parte integrante no dia a dia da gestão do sistema elétrico da empresa.

\footnotetext{
* Contribuição técnica ao $35^{\circ}$ Seminário de Balanços Energéticos Globais e Utilidades e $29^{\circ}$ Encontro de Produtores e Consumidores de Gases Industriais, 13 a 15 de agosto de 2014, São Paulo, SP, Brasil.
} 
Seminário de

Energia \& Utilidades

$35^{\circ}$ Seminário de Balanços Energéticos

Globais e Utilidades \& $29^{\circ}$ Encontro de

Produtores e Consumidores de Gases Industriais

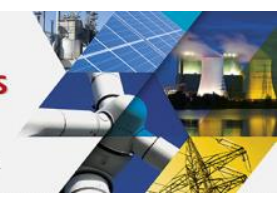

\subsection{Filosofia de Segurança Utilizada}

Para o desenvolvimento adequado dos serviços junto aos clientes foi apresentada, discutida e aprovada por todos os envolvidos a filosofia de segurança que permeia todo o trabalho e que abaixo relatamos.

\subsubsection{Fortalecer a cultura da segurança e os meios para o controle dos riscos}

A segurança não pode ser pensada no momento da execução do trabalho. Toda uma preparação prévia, planejada e estruturada se faz necessária. Criar uma cultura voltada para a saúde e a segurança da equipe é o objetivo.

Sob o ponto de vista de intervenções no sistema elétrico, as ações preventivas, em primeiro lugar, se voltam para o controle dos riscos elétricos e, portanto deve estar sob a responsabilidade dos profissionais da área elétrica: responsável geral pelas instalações, gerentes, supervisores e executantes que se envolvem diretamente na interação com as instalações do sistema elétrico. Basicamente são voltadas para as áreas de Operação e Manutenção.

Os riscos não elétricos ou adicionais (V. item 10.4.2 da NR-10), mas que podem estar presentes no ambiente de trabalho do profissional de eletricidade, também têm que ser identificados e controlados.

Conforme estabelece o item 10.2.1 da NR-10, são requeridos o conhecimento e o domínio das técnicas de análise de tais riscos, devendo ser envolvidos os profissionais da área de Segurança, Saúde e Medicina do Trabalho (SESMT) e os responsáveis pelas áreas Operacionais onde as intervenções ocorrerão (pelo menos a grande maioria delas).

Nesta fase de pensar a segurança é que são definidas entre todas as tarefas passiveis de execução rotineira, aquelas que são críticas, as metodologias de identificação de riscos dessas tarefas, a análise desses riscos e a definição das medidas de controle que certamente passam pelo estabelecimento de comportamentos, do passo-a-passo de execução das intervenções, dos equipamentos de proteção individual e coletiva necessários, instrumentos auxiliares, etc..

São elaborados assim os procedimentos específicos de segurança para trabalhos rotineiros que estabelecerão as diretrizes, formulários e formas de controle da execução dos trabalhos.

Essa forma de pensar a segurança e organizar o trabalho embute a experiência vivida pelos profissionais da PDCA nas áreas de manutenção e operação elétrica em grandes empresas e é norteada pela NR-10, que exige a realização de intervenções apenas após planejamento adequado e o cumprimento de procedimentos específicos, além de serem precedidas de autorização explícita e específica (V. itens NR-10.11.1 e 10.11.2). Assim, prescreve que todo trabalho que exija o ingresso em Zona Controlada (V. Anexo I da NR-10) e aqueles realizados em instalações elétricas, somente podem ser realizados mediante ordem de serviço específica para a data e local, assinada por trabalhador autorizado.

A forma de proceder quando uma intervenção se torna necessária fica assim delineada, minimizando os riscos e aumentando a segurança dos trabalhadores.

\subsubsection{Criar os meios para o controle da execução dos trabalhos com segurança}

A nossa experiência tem mostrado que para um sistema de controle de intervenções adequado, é necessário também sistematizar a forma de solicitações de intervenção, quem está autorizado a solicitá-las, o estabelecimento de uma sequencia priorizada

\footnotetext{
* Contribuição técnica ao $35^{\circ}$ Seminário de Balanços Energéticos Globais e Utilidades e $29^{\circ}$ Encontro de Produtores e Consumidores de Gases Industriais, 13 a 15 de agosto de 2014, São Paulo, SP, Brasil.
} 


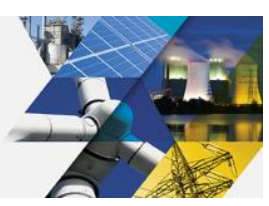

destas solicitações, a definição dos recursos necessários para a sua execução e a sua devida programação em função das disponibilidades do sistema produtivo, se for o caso. Nesta fase, a área elétrica toma conhecimento da necessidade da intervenção e já se prepara previamente, elegendo os executantes e os procedimentos técnicos e de segurança mais adequados.

Após a sua programação, a área elétrica repassa o serviço para a execução, revê as instruções de segurança e os procedimentos que deverão ser seguidos. Cercam-se aqui os riscos elétricos.

Antes de iniciar a intervenção a mesma deve ser autorizada pelo responsável da área operacional onde a mesma será realizada. Algumas empresas empregam o termo Permissão de Trabalho (PT) outras, Permissão para Intervenção em Sistemas (PIS), e assim por diante. O que é mandatório é o espírito do seu conteúdo: executar intervenções seguras no sistema elétrico, tanto sob o ponto de vista de pessoas quanto sob o ponto de vista da continuidade operacional do sistema produtivo, cercando-se também os riscos não elétricos (adicionais) porventura existentes no ambiente do trabalho.

Apresentamos abaixo um Fluxograma Básico (Figura 1) ilustrativo do passo-a-passo na realização de uma intervenção elétrica e da tratativa utilizada no controle de riscos elétricos e dos riscos adicionais envolvidos.

* Contribuição técnica ao $35^{\circ}$ Seminário de Balanços Energéticos Globais e Utilidades e $29^{\circ}$ Encontro de Produtores e Consumidores de Gases Industriais, 13 a 15 de agosto de 2014, São Paulo, SP, Brasil. 
Seminário de Energia \& Utilidades

$35^{\circ}$ Seminário de Balanços Energéticos Globais e Utilidades \& $29^{\circ}$ Encontro de

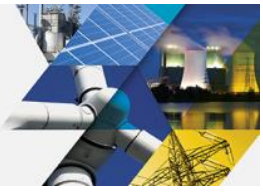

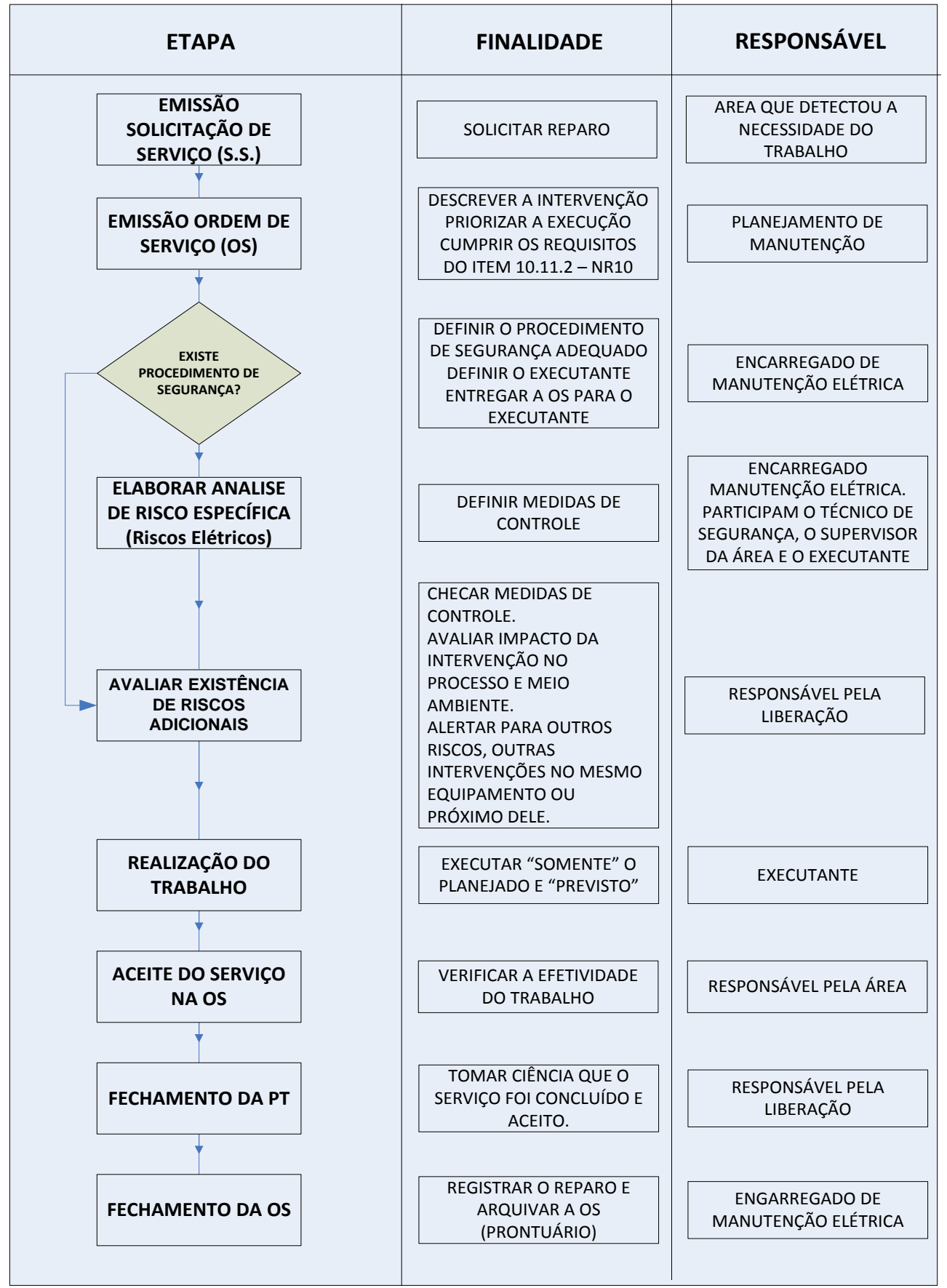

Figura 1 - Fluxograma básico.

\section{RESULTADOS}

A Avaliação do Sistema de Gestão e das Instalações Elétricas, de modo a atender o item 10.2.4.g da NR-10, já havia sido previamente executada pela PDCA nos sites dos seus clientes o relatório conclusivo determinou ações de adequação, como exemplificado abaixo:

- Atualização do Diagrama Unifilar

- Novo estudo de Curto Circuito

- Estudo da Proteção, Coordenação e Proteção do Sistema Elétrico

\footnotetext{
* Contribuição técnica ao $35^{\circ}$ Seminário de Balanços Energéticos Globais e Utilidades e $29^{\circ}$ Encontro de Produtores e Consumidores de Gases Industriais, 13 a 15 de agosto de 2014, São Paulo, SP, Brasil.
} 
- Estudo da Energia Incidente devida a Arcos Elétricos (Arc-Flash)

- Estudo de Classificação de Áreas

- Avaliação e Recomendações para adequação do sistema de aterramento e do SPDA (Sistema de Proteção contra Descargas Atmosféricas)

Desenvolvimento dos seguintes procedimentos:

- Controle de Acesso às Instalações Elétricas

- Segurança Desenergização, Reenergização e Bloqueio de Circuitos Elétricos

- Segurança nos Trabalhos em Instalações Elétricas

- Regras para composição do prontuário das instalações elétricas

- Critérios de Segurança para Projetos de Instalações Elétricas

- Identificação de circuitos, Equipamentos, Subestações e Salas Elétricas

- Procedimentos de Segurança Específicos para Trabalhos Críticos procedimentos)

- Diagramas Unifilares: Tipo e Conteúdo

- Terminologia e Definições - Segurança nos Serviços em Instalações Elétricas

- Avaliação de Sistemas de Aterramento

- Testes de isolação de EPI's e EPC's

- Testes e energização de novas instalações elétricas

\subsection{Procedimento Geral para a Segurança na Execução dos Trabalhos em Instalações Elétricas}

A inexistência de procedimentos de segurança adequados e abrangentes é uma não conformidade encontrada em praticamente todas as empresas por nós avaliadas. A NR-10 enfatiza e torna obrigatórios os procedimentos (V. item NR-10.11.1).

Foi elaborado um Procedimento Geral de Segurança que estabeleceu e detalhou as Medidas de Controle necessárias para eliminar/controlar os riscos nas intervenções elétricas ou reduzi-los a níveis aceitáveis. De acordo com a filosofia mostrada no item 2 , este Procedimento Geral definiu regras básicas a serem seguidas e ações específicas que deverão ser executadas antes e durante a execução dos trabalhos. Em função dos riscos a controlar foram definidos e especificados equipamentos de proteção Individual e coletiva (EPIs e EPCs), bem como ferramentas especificas.

Os itens abaixo detalham as medidas de controle acima enunciadas.

\subsubsection{Regras básicas}
a) Todos os trabalhos em instalações elétricas devem ser executados em conformidade com os requisitos estabelecidos na norma regulamentadora n.10 (NR-10).
b) Todos os trabalhos em instalações elétricas devem ser precedidos de uma Análise de risco
c) Todos os trabalhos deverão ser autorizados mediante a emissão de uma Ordem de Serviço e sua execução é condicionada ao cumprimento de procedimento de segurança específico.

\subsubsection{Ações prévias aplicáveis a serviços rotineiros}
a) Identificação dos trabalhos críticos.
b) Elaboração de Procedimentos de Segurança Específicos para a execução de cada um dos trabalhos críticos.
c) Treinamento dos executantes dos trabalhos nos procedimentos emitidos.

\footnotetext{
* Contribuição técnica ao $35^{\circ}$ Seminário de Balanços Energéticos Globais e Utilidades e $29^{\circ}$ Encontro de Produtores e Consumidores de Gases Industriais, 13 a 15 de agosto de 2014, São Paulo, SP, Brasil.
} 


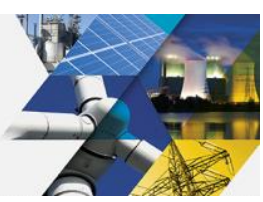

\subsubsection{Identificação dos trabalhos críticos}

a) Identificar todos os trabalhos que são possíveis de serem executadas nas instalações elétricas de cada Unidade Operacional, listando desde os mais simples até os mais complexos, independente do local da sua realização (área operacional, áreas administrativas, oficinas, etc.). Esta identificação deverá ser feita levando em conta as peculiaridades das instalações elétricas em questão.

b) Definir, dentre os trabalhos acima identificados, aqueles considerados Trabalhos Críticos utilizando a metodologia para definição da criticidade dos trabalhos estabelecida institucionalmente pela Empresa.

Nota: Para o estabelecimento da metodologia acima deverá ser constituído um grupo de trabalho especialmente designado para tal fim, que envolva obrigatoriamente profissional da área de segurança. A NFPA 70E 2009 e 2012 - Electrical Safety in the Workplace apresenta uma metodologia que poderá ser utilizado por esse grupo de trabalho como ponto de partida. Esta metodologia considera a frequência de exposição ao risco, a probabilidade da sua ocorrência e a possibilidade de evita-lo. Tais fatores, devidamente ponderados irão definir a classe de risco que junto com a severidade do risco definirão a sua criticidade. Ilustramos abaixo a tabela 1 utilizada para definição da criticidade da intervenção.

- Área negra - Classe crítica - exige a elaboração prévia de procedimentos de segurança escrito conforme item 7.2.2 deste procedimento.

- Área cinza - Classe semi critica - Não exige a elaboração de procedimento prévio de segurança, porem é recomendável analisar com os executantes as medidas de segurança que deverão ser tomadas.

Tabela 1.

\begin{tabular}{|c|c|c|c|c|c|}
\hline \multirow{2}{*}{ Se } & \multicolumn{5}{|c|}{ Classe Cl } \\
\cline { 2 - 6 } & $3-4$ & $5-7$ & $8-10$ & $11-13$ & $14-15$ \\
\hline 8 & \multicolumn{4}{|c|}{} \\
\hline 6 & & & & \\
\\
\hline 3 & & & & \\
\end{tabular}

\subsubsection{Elaboração de análise de risco}
a) Para cada trabalho critico identificado deve ser realizada uma análise de risco utilizando como técnica a Analise Preliminar de Riscos (APR).
b) Para essa análise de risco devem ser envolvidos profissionais que dominem a técnica da APR e também com conhecimento de medidas de controle de riscos elétricos.
c) A análise de risco estabelece as medidas de controle que serão base para a elaboração dos procedimentos de segurança específicos.

\subsubsection{Elaboração de procedimentos de segurança específicos}

a) Os Procedimentos de Segurança Específicos tem o objetivo de estabelecer os requisitos para a execução segura de cada etapa/passo do trabalho.

b) Os procedimentos devem ser padronizados, com descrição detalhada de cada fase da execução (tarefa), passo a passo, e serem assinados pelo profissional legalmente habilitado e aprovado pelo responsável pelas instalações elétricas da Unidade Operacional que o emitiu.

\footnotetext{
* Contribuição técnica ao $35^{\circ}$ Seminário de Balanços Energéticos Globais e Utilidades e $29^{\circ}$ Encontro de Produtores e Consumidores de Gases Industriais, 13 a 15 de agosto de 2014, São Paulo, SP, Brasil.
} 
Seminário de Energia \& Utilidades $35^{\circ}$ Seminário de Balanços Energéticos Globais e Utilidades \& $29^{\circ}$ Encontro de
Produtores e Consumidores de Gases Industriais

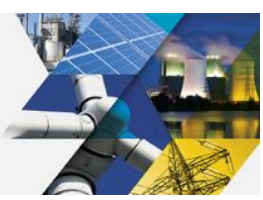

c) Os Procedimentos devem conter, no mínimo: Objetivo, Campo de aplicação, Base técnica, Competências e responsabilidades, Disposições gerais, Medidas de controle e Orientações finais.

d) Os procedimentos devem estar disponíveis para consulta e fazerem parte do Prontuário das Instalações Elétricas.

Apresentamos abaixo um Fluxograma Básico (Figura 2) ilustrativo do passo a passo de um procedimento de segurança específico. No caso ilustramos um procedimento de segurança para trabalhos em painéis elétricos de Baixa Tensão.

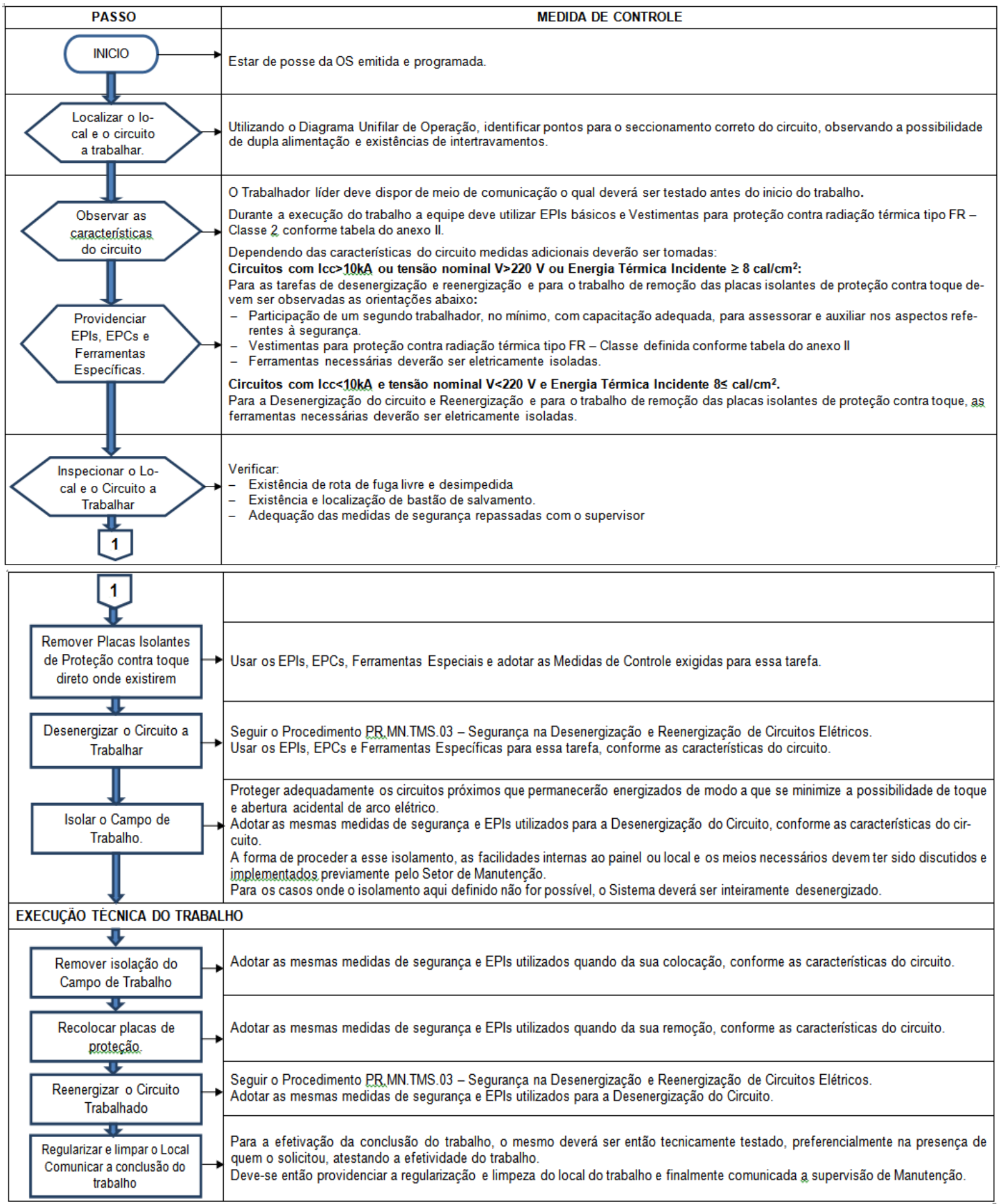

Figura 2 - Fluxograma básico.

\footnotetext{
* Contribuição técnica ao $35^{\circ}$ Seminário de Balanços Energéticos Globais e Utilidades e $29^{\circ}$ Encontro de Produtores e Consumidores de Gases Industriais, 13 a 15 de agosto de 2014, São Paulo, SP, Brasil.
} 


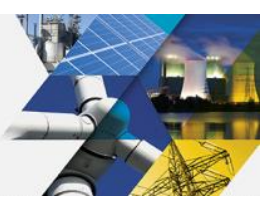

\subsubsection{Treinamento dos executantes}

É obrigatório que os executantes sejam treinados na execução dos Procedimentos. Ele não deve ser somente um treinamento teórico em sala de aula, mas deve ser essencialmente prático, executado no campo, simulando ou acompanhando uma intervenção prática. A reciclagem periódica é importante.

\subsubsection{EPIs, EPCs e Ferramentas Especiais para trabalhos nas Instalações Elétricas.}

a) Os EPIs e os EPCs identificados nas Análises de Risco e Procedimentos devem ser tecnicamente especificados, adquiridos em quantidade suficiente, mantidos e armazenados de forma adequada estando disponíveis aos executantes sempre que necessário.

b) As especificações dos equipamentos de proteção coletiva específicos para trabalhos em eletricidade devem ser claras quanto ao uso, limitações, e características, com ênfase aos aspectos relacionados à segurança com eletricidade: níveis de isolamento, capacidade de corrente suportável pelos conjuntos de aterramento temporário, fixação de barreiras etc..

c) Os equipamentos de proteção individual devem possuir Certificado de Aprovação - CA, segundo a legislação vigente (vide NR-6) a qual deve ser juntada ao prontuário.

d) Cabe ao SESMT da EMPRESA as providencias para o cumprimento do item "a", "b" e "c" acima.

e) As ferramentas para trabalhos em instalações elétricas devem ser isoladas, especificadas e testadas de acordo com a IEC 60900. Os aparelhos de medição (multímetros) deverão ser adequados à grandeza a medir e especificados considerando os aspectos de uso e categoria apropriada ao tipo e local de utilização conforme a IEC-61010.

f) As especificações dos equipamentos de proteção coletiva e de proteção individual assim como o ferramental de uso dos trabalhadores envolvidos com eletricidade devem constar do Prontuário das Instalações Elétricas. Os EPIs e EPCs e ferramentas dotados de isolação elétrica devem ser submetidos periodicamente a testes dielétricos. (ver Procedimentos de Testes em EPIs e EPCs.)

h) Dentre os EPCs, os meios para comunicação são igualmente importantes, devendo estar disponíveis e em perfeitas condições de uso.

\subsubsection{Ações para a execução dos trabalhos com segurança}

\subsubsection{Definição e planejamento dos trabalhos}

- No âmbito da Empresa toda intervenção em instalações elétricas somente poderá ser realizada em função de necessidades que foram previamente detectadas e solicitadas pelos órgãos competentes da sua organização.

- As solicitações de serviço (S.S.) deverão ser formalizadas e o seu atendimento deverá ser programado através de um sistema adequado.

- A programação da execução é formalizada através de uma ORDEM DE SERVIÇO (OS) dirigida aos órgãos executantes os quais deverão prever os recursos necessários, planejar o serviço e fazer constar, entre outros itens, o número do Procedimento de Trabalho a ser utilizado ou o número da ART (Análise de Risco da Tarefa).

\footnotetext{
* Contribuição técnica ao $35^{\circ}$ Seminário de Balanços Energéticos Globais e Utilidades e $29^{\circ}$ Encontro de Produtores e Consumidores de Gases Industriais, 13 a 15 de agosto de 2014, São Paulo, SP, Brasil.
} 


\section{Notas:}

- No momento do planejamento da execução de um trabalho não rotineiro (trabalho incomum), deve ser realizada uma Análise de Risco.

- Avaliar a criticidade desse trabalho e se for o caso incluí-lo na lista de trabalhos críticas e providenciar para que um procedimento de segurança específico seja elaborado.

\subsubsection{Definições para a execução dos trabalhos}

\subsection{Requisitos gerais}

- Os trabalhos a serem realizados nas instalações elétricas deverão ser executados com as mesmas preferencialmente desenergizadas e somente poderão ser executadas por pessoas autorizadas

- Só será considerada instalação elétrica desenergizada aquela que for seccionada, foi impedida de reenergização, foi constatada ausência de tensão, foi providenciado o aterramento temporário e a proteção de elementos energizados caso o trabalho seja executado em proximidade de parte energizada.

- Somente poderão ser executados trabalhos em instalações elétricas energizadas aqueles que por sua natureza exigem ou pressupõem a presença de energia para a sua realização. Entre outros, a desenergização de instalações elétricas é um trabalho em instalação energizada que dever ser considerado crítico.

- Os Procedimentos para trabalhos em instalações energizadas ou suas proximidades, identificados como críticos devem definir, em função da sua criticidade, se esse trabalho pode ou não ser executado individualmente.

- Apenas as operações elementares - como ligar e desligar circuitos elétricos, realizadas em baixa tensão, com materiais e equipamentos elétricos em perfeito estado de conservação, adequados para operação, que em consequência dessa operação não exponham a qualquer risco as pessoas que as realizam, podem ser realizadas por qualquer pessoa não advertida que tenha conhecimento das consequências dessa operação.

- Na execução dos trabalhos é proibido o uso de adornos (metálicos e não metálicos), tais como pulseira, relógio e broches, conforme norma regulamentadora no 10 (NR$10)$, bem como o uso de lentes de contato.

- Em cada sala de painel elétrico ou subestação, devem ser previstos bastão de salvamento ou resgate, luva isolante de borracha, conforme norma ABNT NBR 10622 e manta antichama, instalados em locais de fácil acesso e devidamente identificados.

\subsection{Requisitos específicos para os executantes dos trabalhos nas instalações elétricas}

- Um dos executantes indicado deve ter condições de exercer a supervisão e condução dos trabalhos.

- Os executantes devem estar devidamente autorizados. São considerados autorizados os trabalhadores qualificados ou capacitados e os profissionais habilitados, com anuência formal da empresa.

NOTA: A autorização é um processo administrativo através do qual a empresa declara formalmente sua anuência, autorizando a pessoa a operar em suas instalações elétricas. A autorização está acompanhada da responsabilidade em

\footnotetext{
* Contribuição técnica ao $35^{\circ}$ Seminário de Balanços Energéticos Globais e Utilidades e $29^{\circ}$ Encontro de Produtores e Consumidores de Gases Industriais, 13 a 15 de agosto de 2014, São Paulo, SP, Brasil.
} 


\section{Seminário de Energia \& Utilidades \\ $35^{\circ}$ Seminário de Balanços Energéticos Globais e Utilidades \& $29^{\circ}$ Encontro de
Produtores e Consumidores de Gases Industriais

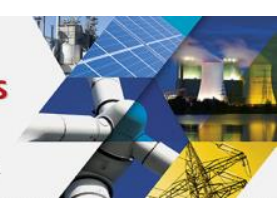

autorizar. Por essa razão é de fundamental importância que a Empresa adote critérios bem claros para assumir tais responsabilidades.

- Os executantes devem ter sido submetidos a exame médico conforme definido no PCMSO da Unidade da Empresa.

- Os executantes devem estar aptos a manusear e operar equipamentos de prevenção e combate a incêndio.

- Os executantes devem estar treinados e capacitados em primeiros socorros decorrentes de acidentes em eletricidade e a queimaduras.

- Os executantes devem portar os EPIs e EPCs previstos nos procedimentos ou na ART específicos para a realização do trabalho.

- Os executantes devem possuir meios de comunicação previstos e estarem treinados na sua utilização.

\section{CONCLUSÃO}

$\mathrm{Na}$ elaboração dos procedimentos de segurança para realização SEGURA das intervenções elétrica em um site industrial, gostaríamos de ressaltar a importância:

- do envolvimento dos profissionais da empresa (alta gerencia e disponibilidade dos especialistas do corpo técnico da empresa);

- da condução dos serviços por parte de empresa contratada / especializada, que estará focada na execução e conclusão destes serviços, diferente do corpo técnico da empresa contratante, que tem como responsabilidade a solução dos problemas do dia-a-dia da manutenção;

- identificação das intervenções críticas, a partir de metodologia específica para este fim (ex. NFPA 70E - 2009 e 2012)

- elaboração de procedimentos específicos para intervenções críticas rotineiras, estabelecendo o passo-a-passo na execução de cada intervenção e as medidas de controle a serem adotadas.

\section{BIBLIOGRAFIA}

1 Ministério do Trabalho e Emprego. Norma Regulamentadora n.10.

2 Pereira JG, Sousa JJB. Manual de auxílio na interpretação e aplicação da NR10 - NR10 Comentada.

3 NFPA 70E: Standard for Electrical Safety in Workplace. Edições de 2009 e 2012.

* Contribuição técnica ao $35^{\circ}$ Seminário de Balanços Energéticos Globais e Utilidades e $29^{\circ}$ Encontro de Produtores e Consumidores de Gases Industriais, 13 a 15 de agosto de 2014, São Paulo, SP, Brasil. 